\title{
Reduced hospital revenue due to error code diagnosis in the implementation of INA-CBGs
}

\author{
Warsi Maryati, Novita Yuliani, Anton Susanto, Aris Octavian Wannay, Ani Ismayani Justika \\ Health Science Faculty, Universitas Duta Bangsa Surakarta, Indonesia
}

\begin{tabular}{l}
\hline \hline Article Info \\
\hline Article history: \\
Received Oct 10, 2020 \\
Revised Feb 12, 2021 \\
Accepted Mar 10, 2021 \\
\hline
\end{tabular}

\section{Keywords:}

Accuracy

Diagnosis

Hospital

INA-CBGs

Rates

\begin{abstract}
In the case-mix system, diagnostic codes are used as the basis for classifying health service rates. The difference in tariffs between hospitals and the accuracy of the diagnosis code causes a gap where there are hospitals that benefit and are disadvantaged by the Indonesian case-based groups (INACBGs) tariff policy. This study assesses the gap factor between hospital rates and INA-CBGs rates, which include hospital characteristics and the accuracy of the diagnosis code. Samples were taken of 100 medical record documents of inpatients at two hospitals in Surakarta, Central Java, Indonesia in 2020 by stratified random sampling. Data were collected by observation and analyzed by Chi-Square test. There were errors in the primary diagnosis code 11 (32.35\%), secondary diagnosis code 19 (55.88\%), combination diagnosis code $4(11.76 \%)$. Changes in the INA-CBG code that caused the inaccuracy of the claim rate were $26(59.09 \%)$ case-mix main groups (CMG) codes, 44 (100\%) CBG-specific codes, 31 (70.45\%) severity level codes. Public-private hospitals with class B experienced a decrease in income of IDR 46,081,900 $(-17.50 \%)$, while special government hospitals with class A experienced an additional income of IDR 99,733,869 (38.31\%). An accurate diagnostic code can increase the odds by 42.128 times the accuracy of the INA-CBGs rate $(b=42.128 ; 95 \% \mathrm{CI}=11.127$ to $159.497 ; \mathrm{p}<0.001)$.
\end{abstract}

This is an open access article under the CC BY-SA license.

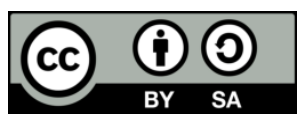

\section{Corresponding Author:}

Warsi Maryati

Health Science Faculty

Universitas Duta Bangsa

Jl. K.H. Samanhudi 93 Sondakan, Laweyan, Surakarta, Central Java Province, Indonesia

Email: warsi_maryati@udb.ac.id

\section{INTRODUCTION}

The diagnosis code has a very important role in determining the cost of health services. A diagnosis code that is not qualified will cause harm to the hospital both financially and in policymaking [1]. Diagnostic codes are very helpful in planning future patient care, making detailed bills for treatment and reducing the risk of hospital management [2]-[5]. Health care cost claims in a case-mix based system in the state of Victoria, Australia depend on a precise, comprehensive and timely diagnosis code. Approximately $16 \%$ of the 752 cases audited showed a change in diagnostic related groups (DRGs) and caused a significant loss to the hospital of AUD 575,300 [6].

Indonesia in its health services has implemented the case-mix system with Indonesian case-based groups (INA-CBGs) in the National health insurance $(J K N)$ program organized by the social security administration $(B P J S)$. INA-CBGs are developed from the case-mix system (case mix) by classifying diagnoses and procedures with the same or similar clinical characteristics and costs. The case-mix system uses tariff grouping based on diagnostic codes according to the International Classification of Diseases and Related Health Problems 10th Revision (ICD-10) [7]. Errors in setting the patient diagnosis code can cause 
changes to the INA-CBGs code so that there are differences in rates. For example, Diabetes mellitus with Ulcer of the skin coded E14.9 and L98.4 generates the INA-CBGS code E-4-10-II at a rate of IDR 6,617,568. The diagnosis code is inaccurate because Diabetes mellitus with complications of Ulcer of skin can be combined with code E14.5 to produce the INA-CBGs code I-4-15-I at a rate of IDR 7,575,541. In one case, the hospital suffered a loss of IDR 957,973. In another case, a pregnant patient with hypertension and anemia coded I10 and D64.9 generated the INA-CBGs code I-4-17-II with a claim rate of IDR 5,885,293. The diagnosis code is inaccurate because hypertension and anemia in pregnant women should be coded O16 and O99.0, which results in the INA-CBGs code W-4-16-I with a claim rate of IDR 2,843,639. In this case, the hospital got a bigger profit of IDR 3,041,654.

Previous studies have shown that the diagnostic codes in general hospitals are significantly more precise than those in specialty hospitals but the number of diagnosis codes with major error types in general hospitals is greater [8]. Thus, each hospital with different characteristics has a different degree of accuracy of the diagnosis code. In addition to the accuracy of the diagnosis code, differences in hospital characteristics such as class, type and hospital ownership lead to differences in the setting of health service rates. The results of the preliminary study show that specialized hospitals, private hospitals and hospitals with a higher class tend to have higher health service rates. The difference in rates between hospitals causes a gap where there are hospitals that benefit and are disadvantaged by the INA-CBGs tariff policy.

Hospitals in the Surakarta City area have different characteristics [9] and based on the preliminary survey the average percentage of inaccurate diagnosis codes is $35 \%$. The percentage of inaccuracy in the diagnosis code is higher than the average of other domestic hospitals, namely 31.5\% [10]-[19] and is still very much higher than overseas hospitals, namely $12.71 \%$ [3]-[6], [8].

Research on the claims of INA-CBGs has been conducted by other researchers before, but only qualitatively analyzed the difference in claim rates based on the diagnosis code. A study was conducted by comparing the impact of secondary diagnostic codes on the performance of diagnostic related groups (DRGs) in Australia and in the US state of Maryland. The results of this study prove that secondary diagnosis codes are more abundant in Maryland, causing the performance of DRGs there to be better than in Australia [20]. Other research has been conducted to review the impact of complication and comorbidity level (CCL) on Korean diagnostic related groups (KDRGs), which results show that as many as $114(19.03 \%), 190(31.72 \%)$ and $295(49.25 \%)$ respectively are included in valid, partially valid and not valid [21]

Researchers have also conducted similar studies with the results that there is a relationship between the accuracy of the diagnosis code and the accuracy of $J K N$ insurance claims [22], however, the researcher did not consider the differences in hospital characteristics and did not describe the impact of inaccurate diagnosis codes on the total hospital revenue obtained from the claims. This study aims to prove the relationship between the accuracy of the diagnosis code and the accuracy of the INA-CBGs claim rate and its impact on hospital income with various characteristics.

\section{RESEARCH METHOD}

This was quantitative research with secondary data analysis and cross-sectional study design. The populations in this study were inpatient medical record documents in 2020. In this study, two hospitals were determined as research sites with consideration of the characteristics of the hospitals. Samples to be taken must meet the inclusion criteria, namely: i) National health insurance inpatient medical record documents in 2020 , ii) Medical record documents that have complete medical information, iii) Medical record documents that are not being used during the treatment period. Samples were taken in two hospitals with different characteristics that were selected by stratified random sampling with 50 documents for each hospital. The variables in this study are; i) The accuracy of the diagnosis code is the diagnosis code in one episode of patient care according to the International Classification of Diseases and Related Health Problems 10th Revision (ICD-10), ii) INA-CBGs rates are package rates based on diagnosis grouping.

Data collection for the accuracy of the diagnosis code was obtained by comparing the diagnosis code contained in the medical record document with the diagnostic code data contained in the INA-CBGs based on ICD-10. The INA-CBG rate data were obtained from comparing the hospital rates with the INACBG grouper rates. The data obtained were written on a checklist sheet to be recapitulated and then analyzed.

Data analysis began with univariate analysis to determine the frequency distribution of each variable, and then continued with bivariate analysis using the Chi-Square test. The stages of this research can be seen in Figure 1. 


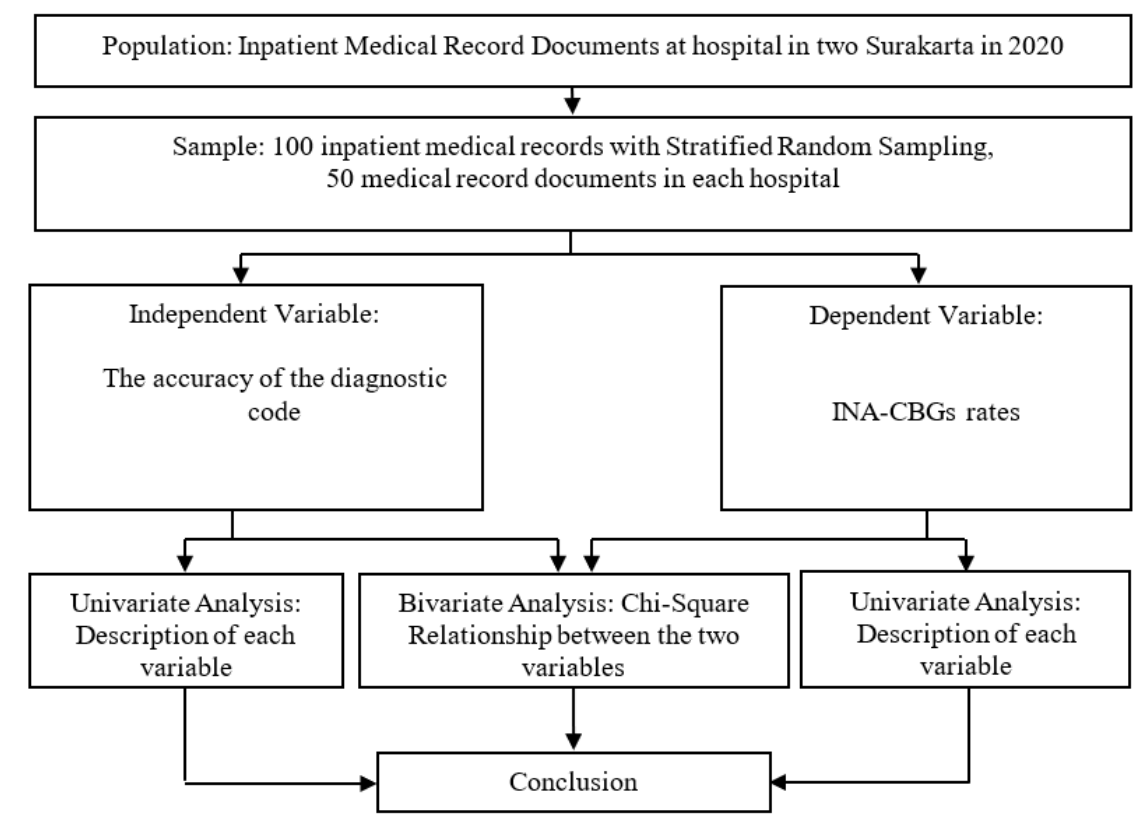

Figure 1. Research flow chart

\section{RESULTS AND ANALYSIS}

\subsection{Hospital characteristic}

The hospital as a place of research has different classes, types and ownership. The first hospital is a public class hospital, B class and private property, while the second hospital is a special hospital, class A and belongs to the Government as shown in Table 1. Each hospital has a different tariff policy for health services. The first hospital, the amount of the hospital service tariff is determined by the Head of the Hospital, while the second hospital is determined by the Central Java Provincial Government. Differences in hospital characteristics such as class, type and hospital ownership lead to differences in the setting of health service rates. Specialized hospitals, private hospitals and hospitals with a higher class tend to have higher health service rates. The difference in rates between hospitals causes a gap where there are hospitals that benefit and are disadvantaged by the INA-CBGs tariff policy.

Table 1. Hospital characteristics and tariff gap

\begin{tabular}{cccl}
\hline Hospital & Class & Type & Ownership \\
\hline $1^{\text {st }}$ Hospital & B & General hospital & Private hospital \\
$2^{\text {nd }}$ Hospital & A & Special hospital & Government hospital \\
\hline
\end{tabular}

\subsection{Diagnosis code accuracy}

The analysis of the accuracy of the diagnosis code on the patient's medical record, there were 34 inaccurate diagnosis codes. The inaccuracy of the diagnosis code was caused by $11(32.35 \%)$ primary diagnosis coding errors, 19 (55.88\%) secondary diagnosis coding errors, 4 (11.76\%) coding errors as shown in Table 2.

Table 2. Factor classification of diagnosis code inaccuracy

\begin{tabular}{lc}
\hline \multicolumn{1}{c}{ Variable } & $\mathrm{n}(\%)$ \\
\hline Major diagnostic coding errors & $11(32.35 \%)$ \\
Secondary diagnostic coding errors & $19(55.88 \%)$ \\
Combination coding error & $4(11.76 \%)$ \\
Total & $34(100 \%)$ \\
\hline
\end{tabular}

Similar results also occur in the external evaluation of coding accuracy in the implementation of the German DRG System. A total of $43.3 \%$ to $54.1 \%$ of the primary diagnoses were rated incorrect, $37.5 \%$ to $74.8 \%$ of the secondary diagnoses were rated incorrect, $85.8 \%$ to $91.7 \%$ were corrected and $49.2 \%$ to $60.5 \%$ 
rated irrelevant to German coding standards. The consequences of potential coding errors in the prospective DRG-based payment system are seen in the daily practice of the hospital [23]. Other research shows that coding errors were found in $89.4 \%(415 / 424)$ of the medical records of selected patients. Coding errors in secondary diagnosis were highest, $81.3 \%$ (377/464), followed by secondary procedures at $58.2 \%(270 / 464)$, primary procedures $50.9 \%$ (236/464) respectively and diagnosis primary amount of 49.8\% (231/464) [24].

\subsection{INA-CBGs rates accuracy}

The case-mix system in Indonesia is implemented with INA-CBGs. The INA-CBGs code consists of an alphabet and numeric combination as follows: i) 1st digit is case-mix main groups (CMG), ii) 2nd digit is case type, iii) 3rd digit is case-specific CBG and iv) The 4th digit in the form of Roman numerals is the severity level. One of the bases for grouping in the INA-CBGs is using the codification of the final diagnosis which becomes the service output [25]. The error diagnosis code can change the INA-CBGs code that appears when grouping is done. Changes in the INA-CBG code that caused the inaccuracy of the claim rate were $26(59.09 \%)$ CMG codes, 44 CBG-specific codes, $31(70.45 \%)$ severity level codes as shown in Table 3 .

Table 3. Changes to INA-CBGs code cause of inaccurate claim rate

\begin{tabular}{lc}
\hline \multicolumn{1}{c}{ Variable } & $\mathrm{n}(\%)$ \\
\hline Change CMG code & $26(59.09 \%)$ \\
Change in case type code & $0(0 \%)$ \\
Change of CBG specific code & $44(100 \%)$ \\
Change in severity level code & $31(70.45 \%)$ \\
Total change of INA-CBGs code & $44(100 \%)$ \\
\hline
\end{tabular}

The same sequence also occurs in the code changes in Malaysia diagnosis related group (MY-DRG) as the cause of inaccurate claims rates, namely changes in DRG Group $131(42.7 \%)$, changes in severity level 87 (28.3\%), changes in CMG 69 (22.5\%), and changes in discipline $12(3.9 \%)$ [24]. This study found that there was no change in the case type code which caused the inaccuracy of the INA-CBGs claim rate. This is because the action code is not analyzed for accuracy, while the action code can determine the case type code in INA-CBGs. Therefore, it is very important for further research to analyze the accuracy of the procedure code.

\subsection{Impact of accuracy of diagnosis codes on hospital revenues in the implementation of INA-CBGs}

The diagnosis code can affect hospital revenues in the implementation of the case-mix system. The diagnosis code is one of the bases for determining the claim rate on INA-CBGs, so that an inaccurate diagnosis code can cause a change in the claim rate. Based on observations on claim data and patient medical record documents, there is a gap between hospital rates and claims rates. The biggest rate gap occurred in the wrong diagnosis code, which resulted in decreased revenues and losses for hospitals.

The first hospital experienced a decrease in income of IDR 46,081,900 (-17.50\%), while the second hospital experienced an additional income of IDR 99,733,869 (38.31\%). An accurate diagnosis code at the first hospital resulted in an additional income of IDR 4,997,400 (3.04\%) and an inaccurate diagnosis code caused a decrease in hospital income by IDR 51,079,300 (-51.55\%). An accurate diagnosis code at the second hospital resulted in an additional income of IDR 98,194,414 (53.65\%) and an inaccurate diagnosis code resulted in an additional hospital income of IDR 1,539,455 (1.99\%) as shown in Table 4.

Table 4. Differences in hospital rates and INA-CBGs claim rates based on the accuracy of diagnosis codes

\begin{tabular}{lcccc}
\hline \multicolumn{1}{c}{ Diagnosis code accuracy } & Hospital tariff (IDR) & INA-CBGs claim tariff (IDR) & Tariff gap (IDR) & Gap percentage (\%) \\
\hline $\mathbf{1}^{\text {st }}$ Hospital A & & & & \\
Accurate & $159,206,500$ & $164,203,900$ & $4,997,400$ & $3.04 \%$ \\
Inaccurate & $150,171,800$ & $99,092,500$ & $-51,079,300$ & $-51.55 \%$ \\
Total & $309,378,300$ & $263,296,400$ & $-46,081,900$ & $-17.50 \%$ \\
$\mathbf{2}^{\text {nd }}$ Hospital & & & & \\
Accurate & $84,840,786$ & $183,035,200$ & $98,194,414$ & $53.65 \%$ \\
Inaccurate & $75,746,745$ & $77,286,200$ & $1,539,455$ & $1.99 \%$ \\
Total & $160,587,531$ & $260,321,400$ & $99,733,869$ & $38.31 \%$ \\
\hline
\end{tabular}

There were $53(80.30 \%)$ accurate codes of diagnosis with the correct INA-CBGs rates, while 13 $(19.70 \%)$ were not correct for the INA-CBGs. Inaccurate diagnosis codes with the correct INA-CBGs rates were $3(8.80 \%)$, while with the incorrect INA-CBGs rates there were $31(91.20 \%)$. The results of the analysis 
show that there is a significant relationship between the accuracy of the diagnosis code and the accuracy of the INA-CBGs tariff. An accurate diagnostic code can increase the chances of 42.128 times the accuracy of the INA-CBGs rate $(b=42.128 ; 95 \% \mathrm{CI}=11.127$ to $159.497 ; \mathrm{p}<0.001)$ as shown Table 5.

Table 5. Analysis of the accuracy of diagnosis codes on the accuracy of INA-CBGs tariff

\begin{tabular}{lccccccc}
\hline \multicolumn{1}{c}{ Diagnosis code } & \multicolumn{2}{c}{ The accuracy of INA-CBGs tariff } & OR & \multicolumn{2}{c}{ CI (95\%) } & p \\
accuracy & Correct (\%) & Incorrect (\%) & Total (\%) & & Lower limit & Upper limit & \\
\hline Accurate (\%) & $53(80.30 \%)$ & $13(19.70 \%)$ & $66(100 \%)$ & \multirow{2}{*}{4.128} & 11.127 & 159.497 & $<0.001$ \\
Inaccurate (\%) & $3(8.80 \%)$ & $31(91.20 \%)$ & $34(100 \%)$ & & &
\end{tabular}

The diagnostic code has a significant impact on claim rates. Inaccurate diagnostic codes increase the risk of decreased revenue for the hospital [25]. Other research shows that a total of 33 studies (53,113 cases) were identified. An average of $23 \%$ of the cases presented coding problems. Eighteen percent of cases result in faulty DRG [26]. Health care cost claims in a case-mix-based system in the state of Victoria, Australia depend on a precise, comprehensive and timely diagnosis code. Approximately $16 \%$ of the 752 cases audited showed a change in diagnostic related groups (DRGs) and caused a significant loss to the hospital of AUD 575,300 [6]. The diagnosis was coded correctly in 103 of 155 cases $(65 \%)$. In 52 cases (35\%) the coding was incorrect or inadequate, in 18 out of 52 cases (12\% overall) it caused a decrease in the DRG value, which was extrapolated on an annual basis, resulting in a loss of DDK 23 million [27]. The ICD-coding correction by the DRG-assistant alone led to a remarkable increase in the case-mix-index (CMI). The mean CMI increased from 1.76 to 1.84 and clinic income increased 180 Euros per patient (a total of about 80,000 Euros in nine weeks). After the end of control, the case-mix-index fell in three weeks to 1.14, corresponding to a potential loss of 1200 Euros per patient [28]. A total of $60.5 \%$ of the diagnostic codes were judged irrelevant to the German coding standard. After review, a remarkable shift in DRG was seen and the case-mix index increased by an average of $6.9 \%(0.25-12.1 \%)$ [23]. Coding error resulted in a different MY-DRG code assignment in $74.0 \%(307 / 415)$ cases. Of these, 52.1\% (160/307) of the cases had lower set hospital rates. In total, the potential loss of revenue due to the MY-DRG coded change is RM 654,303.91 [24].

The main factor causing the inaccurate diagnosis code is the completeness of the resume, medical information and medical support. The completeness of medical information and the accuracy of medical record documents are very important, if the medical information in a medical record document is incomplete, the resulting diagnostic code will be inaccurate [29]. The completeness of writing a diagnosis on a medical resume greatly influences the accuracy of clinical coding [16], [30], [31]. Completeness of medical information can significantly increase the 6.663 times the accuracy of the diagnostic code [32].

\section{CONCLUSION}

Each hospital has set a cost for health services. Public-private hospitals have service rates that tend to be higher than government-owned special hospitals. The error diagnosis code from the highest to the lowest is found in the secondary diagnosis code, main diagnosis code and combination diagnostic code. Due to an error in the diagnostic code, there was a change in INA-CBGs in the CMG code, CBG Specific code and severity level code. Changes in the INA-CBGs have an impact on the income that the hospital receives from claim results. Private hospitals with higher service costs experienced a significant decrease in income, while Government hospitals remained stable despite their income being lower than they should have been. The results of the analysis prove that the accuracy of the diagnosis code has a significant impact on the accuracy of the INA-CBGs claim, while the code of action has not been studied on this occasion, so it is important as an input for further research.

\section{ACKNOWLEDGEMENTS}

Authors would like to thank the Ministry of Research and Technology/National Research and Innovation Agency and the Rector of Universitas Duta Bangsa Surakarta and his staff who have facilitated and financed the publication of this scientific article.

\section{REFERENCES}

[1] World Health Organization, "International Satistical Classification of Diseases and Related Health Problems Tenth Revision," vol. 1, 2 and 3, 2010.

[2] Hatta, G., "Guidelines for Health Information Management in Health Service Facilities," University of Indonesia Press, pp. 53-55, 2013. 
[3] Cummings et al., "Hospital coding of Dementia: is it accurate?," Health Information Management Journal, vol. 40, no. 3, pp. 5-11, 2011.

[4] Dalal. S and Roy. B, "Reliability of Clinical Coding of Hip Facture Surgery: Implications for Payment by Results?," International Journal Care Injured, vol. 40, no. 1, pp. 738-741, 2009.

[5] Thigpen et al., "Validity of International Classification of Disease Codes to Identify Ischemic Stroke and Intracranial Hemorrhage among Individuals with Associated Diagnosis of Atrial Fibrillation," Circulatory Cardiovascular Quaility Outcomes, vol. 8, no. 1, pp. 8-14, 2015.

[6] Cheng, P . Gilchrist, A., Robinson and K.M. Paul, L., "The Risk and Consequences of Clinical Miscoding due to Inadequate Medical Documentation: A Case Study of the Impact on Health Services Funding," Health Information Management Journal, vol. 38, no. 1, pp. 35-46, 2009.

[7] Minister of Health RI. "Regulation of the Minister of Health of the Republic of Indonesia No. 76 of 2016 concerning Guidelines for Indonesian Case Base Groups (INA-CBGs) in the Implementation of National Health Insurance," 2016.

[8] Farzandipour, M. Sheikhtaheri and A. Sadoughi, F., "Effective Factors on Accuracy of Principal Diagnosis Coding Based on International Classification of Diseases, the 10th Revision (ICD-10)," International Journal of Information Management, vol. 30, no. 5, pp. 78-84, 2010.

[9] Minister of Health RI., "Hospital Data Recapitulation," 2019 [Online], Available: http://sirs.yankes.kemkes.go.id/rsonline/report/datars.

[10] Rohman, H. Hariyono and W. Rosyidah, "Policies for Filling Main Diagnoses and Accuracy of Diagnosis Codes on Medical Records at PKU Muhammadiyah Hospital Yogyakarta," KESMAS Journal, vol. 5, no. 2, pp. 162-232, 2011.

[11] Sudra and R.I. Pujihastuti, A., "The Effect of Writing a Diagnosis and Knowledge of Medical Record Officers on Medical Terminology on the Accuracy of Diagnosis Codes," Indonesian Journal of Health Information Management, vol. 4, no. 1, pp. 67-72, 2016.

[12] Arifianto, E. Kresnowati and L. Ernawati, D., "The accuracy of the main diagnostic code of medical record documents in cases of labor with Cesarean section at the Panti Wilasa Citarum Hospital," Journal of Health Vision, vol. 10, no. 2, pp. 84-88, 2011.

[13] Rahayu, H. Ernawati and D. Kresnowati, L. "Accuracy of Main Diagnosis Code in RM 1 Document Medical Record of Karmel Room and Characteristics of Inpatient Coding Officer of Mardi Rahayu Kudus Hospital Period December 2009," Visi Kesehatan Journal, vol. 10, no. 1, pp. 1-5, 2011.

[14] Abiyasa, M.T. Ernawati, D. and Kresnowati, L., "The Relationship between the Specificity of Writing the Diagnosis and the Accuracy of the Code at RM 1 Inpatient Documents at Bhayangkara Hospital Semarang," Journal of Health Vision, vol. 11, no. 2, pp. 99-104, 2012.

[15] Sarwastutik, "Review of the Accuracy of Diagnosis Codes on Inpatient Medical Records Documents with Typhoid Fever Main Conditions Based on ICD-X at PKU Muhammadiyah Delanggu Hospital," Journal of Health Information, vol. 3, no. 2, pp. 8-13, 2013.

[16] Pujihastuti and A. Sudra, R.I., "Relationship of Completeness of Information with Accuracy of Diagnosis and Action Codes in Inpatient Medical Record Documents," Indonesian Journal of Health Information Management, vol. 3, no. 1, pp. 60-64, 2014.

[17] Seruni and F.D.A. Sugiarsi, S., "SWOT Problem Solving Cycle Accuracy of Obstetric Case Diagnosis Codes on Entry and Exit Sheet (RM 1a) Inpatient at Dr. Sayidiman Magetan," Indonesian Journal of Health Information Management, vol. 3, no. 2, pp. 5-13, 2015.

[18] Karimah, R.N. Setiawan and D. Nurmalia, P.S., "Analysis of the Accuracy of Diagnosis Codes of Acute Gastroenteritis Based on Medical Record Documents at the Balung Jember Hospital," Journal of Agromedicine and Medical Sciences, vol. 2, no. 2, pp. 12-17, 2016.

[19] Astuti, R.D., Riyoko and Lena, D., "Review of the Accuracy of Main Diagnosis Codes of Inpatients Based on ICD10 Dahlia Ward at Sukoharjo IV Quarter of 2007 Hospital," Journal of Medical Records, vol. 2, no. 1, pp. 25-30, 2007.

[20] Reid, B., Palmer, G. and Aisbett, C., "Under-Coding in Australia Limits the Performance of DRG Groupers," Health Information Management, vol. 29, no. 3, pp. 113-117, 2000, https://doi.org/10.1177/1833335830002900307.

[21] Maryati, W., "The Relationship between the Accuracy of Diabetes Mellitus Diagnosis Codes and Accuracy of Insurance Claims," Seminar on Health Information Management, APIKES Citra Medika Surakarta, pp. 15-19, 2017.

[22] Kim, S et al., "A review of the complexity adjustments in the Korean Diagnosis-Related Group (KDRG)," Health Information Management Journal, vol. 49, no. 1, pp. 62-68, 2020, doi:10.1177/18333558318795804.

[23] Dirschedl, P., Reichle, M., Röther, M. "Model project on coding accuracy," Gesundheitswesen, vol. 65, no. 1, pp. 1-7, 2003, doi: 10.1055/s-2003-36914.

[24] Zafirah SA, Nur AM, Puteh SEW and Aljunid SM, "Potential loss of revenue due to errors in clinical coding during the implementation of the Malaysia diagnosis related group (MY-DRG) Casemix system in a teaching hospital in Malaysia," BMC Health Services Research, vol. 18, no. 1, pp. 38, 2018, doi: 10.1186/s12913-018-2843-1.

[25] Callen J, Meehan J and Tomornsak S.,"Looking to CQI for improvements in clinical documentation and coding," Health Inf Manag, vol. 27, no. 1, pp. 7-11, 1997, doi: 10.1177/183335839702700105.

[26] Lüngen M and Lauterbach KW., "Extent and causes of coding problems for total compensation on the basis of Diagnosis-Related Groups," Deutsche Medizinische Wochenschrift, vol. 126, no. 51-52, pp. 1449-53, 2001, doi: 10.1055/s-2001-19213. 
[27] Nymark T, Thomsen K, and Röck ND., "Diagnosis and procedure coding in relation to the DRG system," Ugeskrift Laeger., vol. 165, no. 3, pp. 207-209, 2003.

[28] Reng CM, Blaas S, Bregenzer N, Hammond A and Schlottmann K., "Effects of contemporaneous control of DRGrelevant coding by physicians," Deutsche Medizinische Wochenschrift, vol. 128, no. 40, pp. 2059-64, 2003, doi: $10.1055 / \mathrm{s}-2003-42704$.

[29] Nurhanifah, D., "Factors Associated with Diabetic Foot Ulcer in Diabetic Foot Polyclinic," Healthy Mu Journal, vol. 1, no. 1, pp. 32-41, 2017.

[30] Pepo, H and Yulia, "Completeness of Writing a Diagnosis on a Medical Resume Against the Clinical Coding of Obstetrics Cases,” Jurnal Manajemen Informasi Kesehatan Indonesia, vol 3, no 2, pp. 78-80, 2015.

[31] Maryati, W. "Relationship Between Physician Characteristics and Completeness of Entry-Out Summary Sheet," Jurnal Manajemen Informasi Kesehatan, vol. 3, no. 1, pp. 26-35, 2014.

[32] Maryati, W., Wannay, A.O, and Suci, D.P., "Relationship to Completeness of Medical Information and Accuracy of the Diagnosis Code of Diabetes Mellitus," Jurnal Rekam Medis dan Informasi Kesehatan, vol. 1, no. 2, pp. 96108, 2018. 